\title{
DIET OF THE BLACK-BEARDED TOMB BAT TAPHOZOUS MELANOPOGON TEMMINCK, 1841 (CHIROPTERA: EMBALLONURIDAE) IN INDIA
}

\author{
Bhargavi Srinivasulu ${ }^{1}$ and C. Srinivasulu ${ }^{2}$ \\ 1,2 Wildlife Biology Section, Department of Zoology, Osmania University, Hyderabad, Andhra Pradesh 500007, India \\ Email: ${ }^{1}$ bharisrini@yahoo.co.in; ${ }^{2}$ hyd2_masawa@sancharnet.in
}

\begin{abstract}
The dietary composition of the Black-bearded Tomb Bat Taphozous melanopogon Temminck, 1841 (Chiroptera: Emballonuridae) from two different habitats was analyzed following faecal pellet analysis method. Representatives of 11 insect orders and spiders (Araneidae) contributed to the diet. Forest bats fed on 1-9 insect orders and araneids indicating opportunistic feeding behaviour, while the semi-urban bats fed on 3-8 insect orders and araneids indicating selective feeding behaviour. Although both the forest bats and semi-urban bats fed on the same spectrum of insect prey they showed differential use of them. Forest bats fed predominately on Coleoptera, Homoptera, Lepidoptera, Hemiptera, Orthoptera, Odonata and Araneidae, while the semi-urban bats preferred Lepidoptera, Coleoptera, Diptera, Orthoptera, Odonata, Hemiptera, Araneidae and Homoptera. Variation in terms of consumption of a particular kind of insect prey between the sexes was evident only among the semi urban bats only with respect to the most significant prey items coleopterans, lepidopterans and dipterans.
\end{abstract}

\author{
KEYWORDS \\ Andhra Pradesh, Black-bearded Tomb Bat, Borra caves, diet, Emballonuridae, faecal pellet analysis, feeding \\ preference, Microchiroptera, semi-urban area, Taphozous melanopogon
}

The Black-bearded tomb bat Taphozous melanopogon Temminck, 1841 (Chiroptera: Emballonuridae) is a widespread species distributed in South and Southeast Asia. In India, it is one of the common bats known from many localities. This bat is a highly gregarious species living in diurnal roosts in caves, ruins and temples, with a colony size varying from ten individuals to many hundreds (Brosset, 1962; Hill, 1967; Sapkal \& Khamre, 1984; Bates \& Harrison, 1997; Molur et al., 2002). Bates and Harrison (1997) opined that there exists no information on their diet within the Indian subcontinent. Excepting Zubaid (1990), who worked out the dietary composition of this bat in Malaysia, no other information on the dietary composition of Black-bearded Tomb Bat exists.

Information of the diet of bats gives us a clear understanding of the ecology and their feeding behaviour (Kurta \& Whitaker, 1998). Bats tend to be selective of their prey, the abundance of which in turn differs spatially, temporally and seasonally (Whitaker et al., 1996). Various other factors such as the size of the prey and the mode in which the prey presents itself tends to govern the dietary composition and feeding behaviour of the bat (Verts et al., 1999). It has been observed that bats switch between selective feeding and opportunistic feeding depending on the availability of preferred prey and availability of prey base alone (Whitaker, 1995; Whitaker et al., 1999).

As a part of the project envisaged to study the diet of select microchiropteran species and to highlight their ecological importance, we analyzed the diet of the Black-bearded Tomb Bat from two different habitat conditions to understand variations in diet composition with respect to prey availability in these habitats.

\section{STudy Area}

We studied the forest bats roosting at Borra caves - located $92 \mathrm{~km}$ off Visakhapatnam in the Ananthagiri Hills, Visakhapatnam district, Andhra Pradesh from where the bats were netted to collect faecal samples from 2 March to 16 March 2003. The environs surrounding Borra caves is predominately forest ecosystem with 10-15\% agriculture expanse and human settlements. Semi-urban bats were mist netted in the northern Secunderabad area, Ranga Reddy District, Andhra Pradesh. Mist nettings were carried out on 14 nights from 18 March to 2 April 2003. The semi urban environs of northern Secunderabad is represented by farmlands, orchards, vineyards, human settlements and scrub jungle.

\section{MethODS}

To collect faeces bats were captured either using hoop nets or mist nets at the roosting sites between 2100 and 2400hr in both the study sites. Trapped bats were placed separately in clean cotton cloth bags for about an hour and a half, after which they were released. Faeces was transferred from the bags to separate dry tubes for each individual bat. Faecal samples were collected on each night from three individuals of either sex from each study site amounting to 30 individuals (15 individuals of either sex) from each site ( 3 males +3 females $x 5$ trap nights). All pellets collected from a single individual were considered a single unit and were analysed following the methodology described by Whitaker (1988). Each pellet was examined separately and the insect remains were identified to family, which is normally the lowest taxonomic level possible, or when it was not possible, to order following Mani (1990), Shiel et al. (1997) and Whitaker (1988). The results are presented as overall percent volume [(sum of individual volumes/total volume for the sample) $x$ 100], and percentage frequency [(number of pellets of 
occurrence/total number of pellets in sample) x 100] (Whitaker, 1988; Paul Racey, July 2004, pers. comm.). Reference collections of insects from both the study areas were made using light traps and sweep nets for species identification. Beetles entangled in mist nets were also collected.

Percentage data were arcsine transformed before subjecting to statistical analyses to correct non-normality (Zar, 1984). Oneway ANOVA and Scheffe's test were used to determine the differences in percentage data between habitats and between sexes in each habitat (Sokal \& Rohlf, 1995).

\section{RESults}

The overall composition of food items taken by the Blackbearded Tomb Bat Taphozous melanopogon Temminck, 1841 as identified in faecal pellets including representatives of 11 insect orders and Araneidae (spiders) varied significantly between the forest and semi urban habitats (Table 1). The most significant differences were in percentage volume of lepidopterans, homopterans and dipterans $(p<0.01)$ in the diet composition. With respect to percentage frequency, besides these three insect groups, variations were also noted in orthopterans and odonates (both, $\mathrm{p}<0.01$ ), and hemipterans, coleopterans and araneids (all, $\mathrm{p}<0.05)$.

In the forest habitat, the coleopterans ranked first in percentage volume (Mean $=52.3$; Range: 33.16 to $78.33 ; \mathrm{n}=5$ ) followed by lepidopterans $($ Mean $=17.2$; Range: 12.33 to $25.16 ; \mathrm{n}=5$ ), homopterans $($ Mean $=8.16$; Range: 0 to $17.33 ; \mathrm{n}=5)$, orthopterans $($ Mean $=4.8$; Range: 1.66 to $11.33 ; \mathrm{n}=5)$, hemipterans $($ Mean $=4.33$; Range: 0.33 to $7.5 ; \mathrm{n}=5)$, and odonates (Mean $=3.66$; Range: 1.33 to $5.0 ; n=5)$. In the semi urban habitat, lepidopterans ranked first (Mean $=39.63$; Range: 38.0 to $41.33 ; \mathrm{n}=5$ ) followed by coleopterans (Mean $=37.56$; Range: 32.83 to $44.33 ; \mathrm{n}=5$ ), dipterans (Mean $=6.93$; Range: 4.33 to $9.33 ; n=5)$ and orthopterans (Mean $=6.63$; Range: 3.33

Table 1. Diet of Black-bearded Tomb Bat Taphozous melanopogon in two different habitats in India. Food types where consumption as percentage volume or percentage frequency varied significantly between the habitats are indicated with asterisk $\left({ }^{*} p<0.05 ;{ }^{*} p<0.01\right)$. Significance is based on univariate ANOVA for each type of food. All pellets (2-6 numbers) collected from each individual bat are considered a single unit.

\begin{tabular}{|c|c|c|c|c|}
\hline \multirow{2}{*}{$\begin{array}{l}\text { Habitat } \\
\text { Food }\end{array}$} & \multicolumn{2}{|c|}{ Forest $(n=30)$} & \multicolumn{2}{|c|}{ Semi Urban $(n=30)$} \\
\hline & Volume & Frequency & Volume & Frequency \\
\hline Coleoptera & 52.3 & $86.66^{*}$ & 37.56 & $100.00^{*}$ \\
\hline Lepidoptera & $17.2^{* *}$ & $36.66^{* *}$ & $39.63^{* *}$ & $100.00^{* *}$ \\
\hline Homoptera & $8.16^{\star \star}$ & $43.33^{\star *}$ & $0.4^{* *}$ & $33.33^{* *}$ \\
\hline Orthoptera & 4.8 & $33.33^{* *}$ & 6.63 & $80.00^{* *}$ \\
\hline Hemiptera & 4.33 & $36.66^{*}$ & 2.26 & $70.00^{*}$ \\
\hline Odonata & 3.66 & $33.33^{* *}$ & 3.7 & $76.66^{\star *}$ \\
\hline Araneidae & 2.76 & $33.33^{*}$ & 2.5 & $66.66^{*}$ \\
\hline Diptera & $2.33^{* *}$ & $26.66^{\star *}$ & $6.93^{* *}$ & $96.66^{\star *}$ \\
\hline Dermoptera & 2.16 & 23.33 & 0.0 & 0.0 \\
\hline Trichoptera & 0.83 & 20.00 & 0.2 & 20.00 \\
\hline Neuroptera & 0.76 & 13.33 & 0.16 & 16.66 \\
\hline Ephemeroptera & 0.66 & 6.66 & 0.0 & 0.0 \\
\hline
\end{tabular}

to $8.83 ; \mathrm{n}=5$ ). With respect to percent frequency, in the forest habitat coleopterans again ranked first (Mean $=86.66$; Range: 66.66 to $100 ; n=5$ ) followed by homopterans (Mean $=43.33$; Range: 33.33 to $50.00 ; \mathrm{n}=5$ ), lepidopterans and hemipterans (both, Mean $=36.66$; Range: 16.66 to $50.00 ; n=5$ ). In the semi urban habitat lepidopterans and coleopterans contributed $100 \%$ of the faecal samples analysed. Other major contributors in terms of percent frequency were by dipterans (Mean $=96.66$; Range: 83.33 to $100.00 ; n=5)$, orthopterans $($ Mean $=80.00$; Range: 50.00 to $100.00 ; \mathrm{n}=5$ ) and odonates (Mean $=70.00$; Range: 66.66 to $83.33 ; \mathrm{n}=5$ ).

No significant variation in percent volume contribution to diet by various insect orders between habitats was observed excepting the orders Diptera, Homoptera and the Lepidoptera (Sheffe's test statistics ranging from 14.68 to 16.06, in all cases $\mathrm{p}<0.01$ ). In case of percent frequency significant variation was noted in orders Orthoptera, Odonata, Diptera and Lepidoptera (Sheffe's test statistics ranging from 16.52 to 62.39 , in all cases $\mathrm{p}<0.01$ ), and in orders Hemipetra, Coleoptera, and Araneidae (Sheffe's test statistics ranging from 4.46 to 7.29 , in all cases $\mathrm{p}<0.05)$.

\section{Discussion}

We presume that the bats in the semi-urban ecosystem tend to be more selective in their preference of the prey species irrespective of prey availability. This trend indicates prey preference being habitat specific as indicated by Kurta \& Whitaker (1998). The diet of forest bats included 11 insect orders and Araneidae. The preferred insect orders in the diet of the forest bats ranged between 1-9 insect orders (male: 1-8 orders; females: 1-9 orders). In the semi-urban ecosystem, only nine insect orders and Araneidae were consumed. The preferred insect orders in the diet of the semi-urban bats ranged between 3-8 insect orders (males: 3-7 orders; females: 5-8 orders). Prey belonging to two insect orders namely Dermoptera and Ephemeroptera were absent in the diet of bats from semi-urban ecosystem although they were represented in insect samples collected during the study. The forest bats consumed less number of spiders (one-third vs. two-third percent frequency; $\left.\mathrm{F}_{1,58}=7.25, \mathrm{p}<0.01\right)$ than the semi-urban bats. This finding indicates that forest bats are opportunistic feeders while semiurban bats are selective feeders. Although bats from both the habitats consumed same prey items they showed differential use of them.

Among the forest bats no variation in either percentage volume or percent frequency of diet components were noted between the males and the females. Although no significant variation was noted in percent frequency of the dietary components of semi-urban bats, a significant variation in percent volume of Coleoptera $\left(\mathrm{F}_{1,28}=12.66, \mathrm{p}<0.01\right)$; Lepidoptera $\left(\mathrm{F}_{1,28}=5.10\right.$, $\mathrm{p}<0.05)$ and Diptera $\left(\mathrm{F}_{1,28}=4.36, \mathrm{p}<0.05\right)$ between males and females were observed (Fig. 1).

The dietary composition of Taphozous melanopogon in forest ecosystems is predominated by Coleoptera, Homoptera, Lepidoptera, Hemiptera, Orthoptera, Odonata, and Araneidae, 


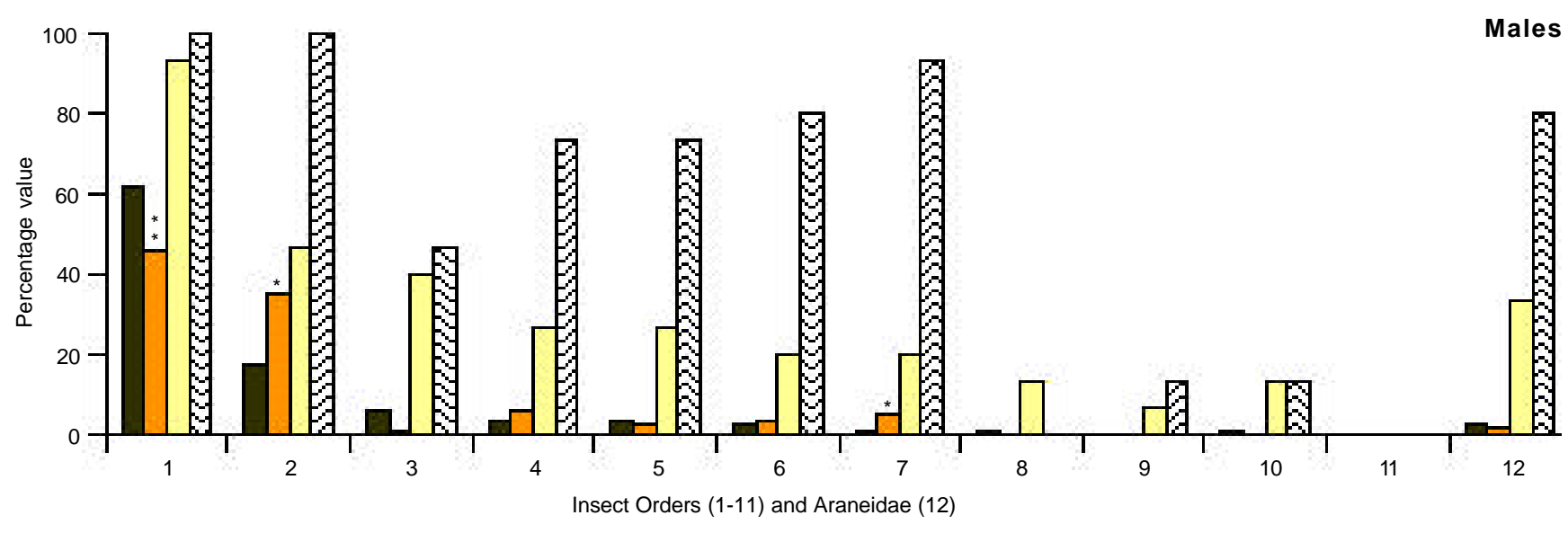

口 \% Volume (Forest) $\quad$ \% Volume (Semi Urban) $\quad \square$ \% Frequency (Forest) \% Frequency (semi Urban)

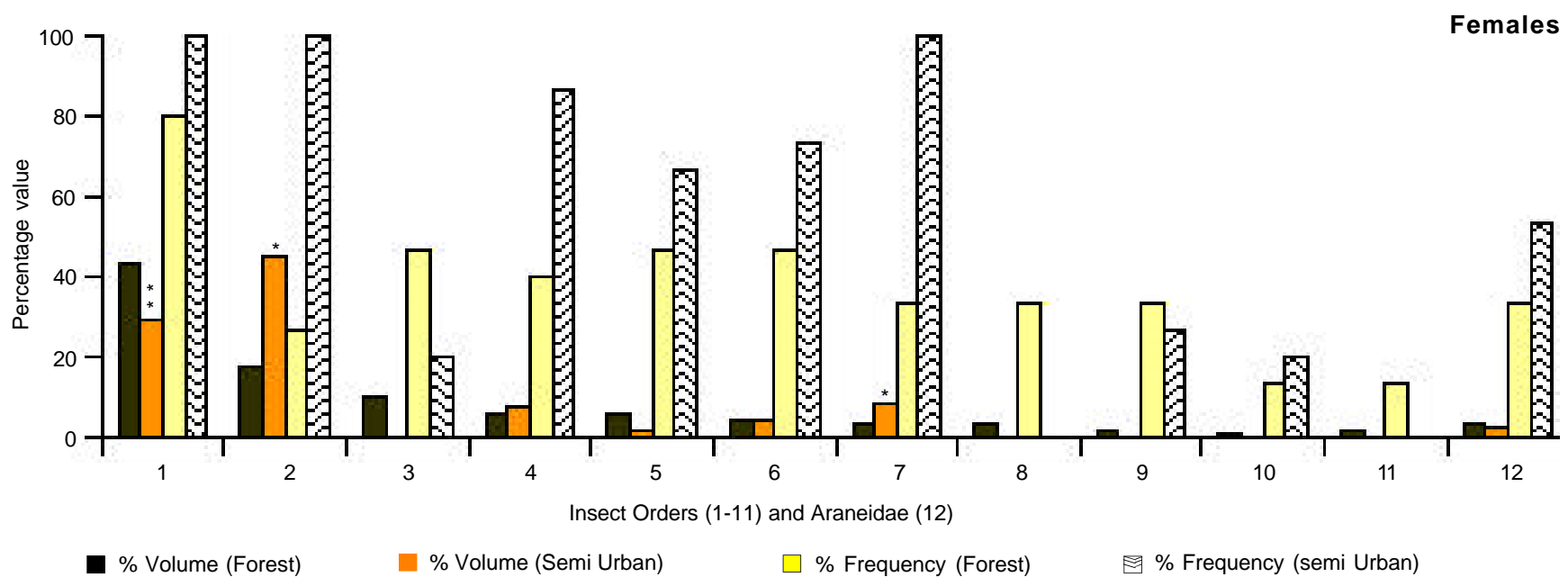

1 - Coleoptera; 2 - Lepidoptera; 3 - Homoptera; 4 - Orthoptera; 5 - Hemiptera; 6 - Odonata; 7 - Diptera; 8 - Dermoptera; 9 - Trichoptera; 10 - Neuroptera; 11 Ephemeroptera; 12 - Araneae

Figure 1. Sex wise variation in diet of Taphozous melanopogon in two different habitats in India. Food types where consumption as percentage volume or percentage frequency varied significantly between the sexes in specific habitat are indicated with asterisk $\left({ }^{*} p<0.05\right.$; $\left.{ }^{* *} p<0.01\right)$. Significance is based on univariate ANOVA for each type of food.

while in semi-urban ecosystem the diet was predominated by Lepidoptera, Coleoptera, Diptera, Orthoptera, Odonata, Hemiptera, Araneidae, and Homoptera. This variation in dietary composition of the same species of microchiropteran bat from two different habitat types indicate that the bats adjust their feeding repertoire with diversity and availability of insect prey. In forest habitat they were more of opportunistic feeders preying up on insects that they encountered, an observation agreeing with that of Zubaid (1990), while in semi urban habitat they preferred insects of a size that met their dietary requirements. The present study also reveals that the roosting conditions too control the feeding behaviour of the bats. In forest habitat type the bats roosted in large colonies (in many clusters of mixed or segregated sexes, each cluster with $>200$ individuals) in Borra caves along with five other microchiropterans, while in the semi-urban habitat they roosted in small colonies $(<100$ individuals) in dilapidated houses and old temples. Zubaid (1990) also observed that Black-bearded Tomb Bats roosting in caves were generalist feeders. Predominance of lepidopterans, coleopterans, dipterans and orthopterans in the diet of Blackbearded Tomb Bat indicates its importance in controlling important insect pests near human habitation and agro ecosystems as revealed by the diet of semi-urban bats in the present study.

\section{REFERENCES}

Bates, P.J.J. and D.L. Harrison (1997). Bats of the Indian Subcontinent. Harrison Zoological Museum, Sevenoaks, Kent, U.K., 258pp.

Brosset, A. (1962). The bats of central and western India. Part I. Journal of the Bombay Natural History Society 59: 1-57.

Hill, J.E. (1967). The bats of the Andaman \& Nicobar Island. Journal of the Bombay Natural History Society 64: 1-9. 
Kurta, A. and J.O. Whitaker, Jr. (1998). Diet of the endangered Indiana Bat (Myotis sodalis) on the northern edge of its range. American Midland Naturalist 140: 280-286.

Mani, M.S. (1990). General Entomology. Oxford-IBH Publishing, New Delhi, 912pp.

Molur, S., G. Marimuthu, C. Srinivasulu, S. Mistry, A.M. Hutson, P.J.J. Bates, S. Walker, K. Padma Priya and A.R. Binu Priya (Eds.) (2002). Status of South Asian Chiroptera - Conservation Assessment and Management Plan (C.A.M.P.) Workshop Report 2002. Zoo Outreach Organisation, CBSG - South Asia and WILD, Coimbatore, India, viii+141pp+CD-Rom.

Sapkal, V.M. and K.G. Khamre (1984). Breeding habits and associated phenomenon in some Indian bats. Part 8 - Taphozous melanopogon (Temminck) - Emballonuridae. Journal of the Bombay Natural History Society 80: 303-311.

Shiel, C., C. McAney, C. Sullivan and J. Fairley (1997). Identification of Arthropod Fragments in Bat Droppings. Occasional Publication No. 17. The Mammal Society, London, 57pp.

Sokal, R.R. and F.J. Rohlf (1995). Biometry: The Principles and Practice of Statistics and Biological Research. $3^{\text {rd }}$ edition. W. H. Freeman \& Co., New York.

Verts, B.J., L.N. Carraway and J.O. Whitaker Jr. (1999). Temporal variation in prey consumed by Big Brown Bats (Eptesicus fuscus) in a maternity colony. Northwest Science 73(2): 114-120.

Whitaker, J.O. Jr. (1995). Food availability and opportunistic versus selective feeding in insectivorous bats. Bat Research News 35: 75-77. Whitaker, J.O. Jr. (1988). Food habits analysis of insectivorous bats, pp. 171-189. In: Kunz, T.H. (ed.) Ecological and Behavioural Methods for the Study of Bats. Smithsonian Institution Press, Washington DC., $533 \mathrm{pp}$.

Whitaker, J.O. Jr., C. Neefus and T.H. Kunz (1996). Dietary variation in the Mexican Free-tailed Bat (Tadarida brasiliensis mexicana). Journal of Mammology 77(3): 716-724.

Whitaker, J.O. Jr., S. Suthakar Issac, G. Marimuthu and T.H. Kunz (1999). Seasonal variation in the diet of the Indian Pygmy Bat, Pipistrellus mimus, in southern India. Journal of Mammology 80(1): 60-70.

Zar, J.H. (1984). Biostatistical analysis. $2^{\text {nd }}$ edition. Prentice-Hall, New Jersey, $717 \mathrm{pp}$.

Zubaid, A. (1990). Food and roosting habits of black-bearded tomb bat, Taphozous melanopogon (Chiroptera: Emballonuridae) from Peninsular Malaysia. Mammalia 54(1): 159-162.

\section{ACKNOWLEDGement}

We thank the Andhra Pradesh Tourism Department Corporation in extending facilities and hospitality during our visit to Borra caves, Visakhapatnam. The Head, Department of Zoology and Prof. V. Nagulu, of Osmania University provided necessary facilities and encouragement. We also thank Prof. Paul Racey, University of Aberdeen, United Kingdom for insights and stimulating discussions. We acknowledge the Council for Scientific and Industrial Research, New Delhi for individual Research Associateship grants.

\section{Volunteers needed}

\section{The Chiroptera Conservation and}

Information Network of South Asia (CCINSA) along with Dr. Shahroukh Mistry, USA, have embarked on a project that involves identification and monitoring of fruit bat (Pteropus giganteus) colonies/ roosts all over South Asia. The project will be an ongoing one with regular monitoring of colonies to understand the dynamics, population trends and various other aspects of the region's largest bats.

If you or any one of your colleagues or friends are interested in joining this exciting project, please write with your name, address, occupation, interest in this subject, and the geographical area you would like to participate in monitoring fruit bats.

We already have a few volunteers who have started work in different parts of South Asia. South Asia is a large region and we need many more people.

Write to us at the earliest to be part of this long-term, first of its kind project:

\section{Ptero Count}

Sanjay Molur / Sally Walker / Sripathi

Kandula (Scientific Chair)

CCINSA

Zoo Outreach Organisation

29-1 Bharathi Colony

Peelamedu

Coimbatore 641004

Email: herpinvert@vsnl.com, zooreach@vsnl.com

Ph: +91 422 2568906, 2561743, 2561087

Fx: +914222563269 